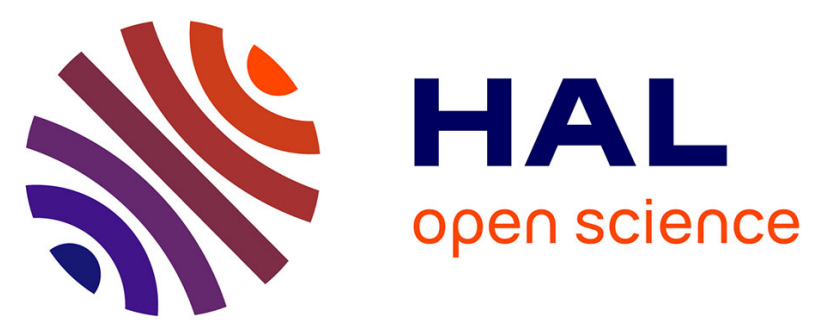

\title{
Study of electron field emission from arrays of multi-walled carbon nanotubes synthesized by hot-wire dc plasma-enhanced chemical vapor deposition
}

Costel Sorin Cojocaru, Dohyung Kim, Didier Pribat, Jean Eric Bouree, Eric Minoux, Laurent Gangloff, Pierre Legagneux

\section{To cite this version:}

Costel Sorin Cojocaru, Dohyung Kim, Didier Pribat, Jean Eric Bouree, Eric Minoux, et al.. Study of electron field emission from arrays of multi-walled carbon nanotubes synthesized by hot-wire dc plasma-enhanced chemical vapor deposition. Journal of Non-Crystalline Solids, 2006, 352, pp.13521356. 10.1016/J.JNONCRYSOL.2006.01.065 . hal-00541131

\section{HAL Id: hal-00541131 \\ https://hal.science/hal-00541131}

Submitted on 2 Mar 2013

HAL is a multi-disciplinary open access archive for the deposit and dissemination of scientific research documents, whether they are published or not. The documents may come from teaching and research institutions in France or abroad, or from public or private research centers.
L'archive ouverte pluridisciplinaire HAL, est destinée au dépôt et à la diffusion de documents scientifiques de niveau recherche, publiés ou non, émanant des établissements d'enseignement et de recherche français ou étrangers, des laboratoires publics ou privés. 


\title{
Journal of Non-Crystalline Solids \\ 352 (2006) 1352-1356 \\ DOI: http://dx.doi.org/10.1016/j.jnoncrysol.2006.01.065
}

\section{Study of electron field emission from arrays of multi-walled carbon nanotubes synthesized by hot-wire dc plasma-enhanced chemical vapor deposition}

\author{
Costel Sorin Cojocaru ${ }^{a}$, Dohyung Kim ${ }^{a}$, Didier Pribat ${ }^{a}$, Jean-Eric Bourée ${ }^{\mathrm{a}, *}$, \\ Eric Minoux ${ }^{b}$, Laurent Gangloff ${ }^{b}$, Pierre Legagneux ${ }^{b}$ \\ a Laboratoire de Physique des Interfaces et des Couches Minces, CNRS UMR 7647, Ecole Polytechnique, F-91128 Palaiseau cedex, France \\ b THALES Research and Technology, Route Départementale 128, F-91767 Palaiseau cedex, France
}

\begin{abstract}
Multi-walled carbon nanotubes have been grown on $7 \mathrm{~nm} \mathrm{Ni-coated} \mathrm{substrates} \mathrm{consisting} \mathrm{of} 300 \mathrm{Im}$ thick highly n-doped ( 1 o o) silicon covered with a diffusion barrier layer (10 nm thick) of $\mathrm{SiO}_{2}$ or $\mathrm{TiN}$, by combining hot-wire chemical vapor deposition and direct current plasma-enhanced chemical vapor deposition at low temperature (around $620^{\circ} \mathrm{C}$ ). Acetylene gas was used as carbon source and ammonia and hydrogen were used either for dilution or etching. Growth of dense aligned nanotubes could be observed only if the ammonia content was minimized ( $\left.v_{5} \%\right)$. In order to improve the electron field emission properties of the films, different geometrical factors have been taken into account: average length, length/radius ratio and spacing between nanotubes. The nanotube growth rate was controlled by the substrate temperature and the pressure in the reactor, and the nanotube height by the growth time. The nanotube diameter was controlled by the catalyst dot volume, and the nanotube spacing was adjusted during the patterning process of the catalyst dots. Using optical lithography, $1 \mathrm{Im}$ Ni dots were obtained and several multi-walled nanotubes with diameter and length in the range 6o$120 \mathrm{~nm}$ and $\mathrm{rV} 2.3 \mathrm{Im}$ were grown on each dot. Thus, based on a two-dimensional square lattice with a lattice translation vector of $4 \mathrm{Im}$, I-V characteristics yielded an onset electric field of $16 \mathrm{~V} / \mathrm{Im}$ and a maximum emission current density of $40 \mathrm{~mA} / \mathrm{cm}^{2}$, due to the large screening effect. Using electron-beam lithography, $100 \mathrm{~nm} \mathrm{Ni}$ dots were obtained and individual multi-walled nanotubes were grown on each dot. Based on a square lattice with $10 \mathrm{Im}$ translation vector, I-V characteristics gave an onset field of $8 \mathrm{~V} / \mathrm{Im}$ and a maximum emission current density of $0.4 \mathrm{~A} / \mathrm{cm}^{2}$.
\end{abstract}

Keywords: Catalysis; Chemical vapor deposition; Plasma deposition; Scanning electron microscopy; Carbon-based nanotubes

\section{Introduction}

Carbon nanotubes (CNTs) are graphitic tubules with nanometer-size diameters and have a very large aspect ratio (length/radius). They exhibit highly anisotropic physical properties, specifically excellent field emission properties (high local electric field due to nanometer-size radius of curvature at the CNT's apex), which make them attractive as potential electron sources in various vacuum electronic applications. To take optimal benefit of the field enhancement factor, defined by the ratio (local electric field)/ (applied field), relatively low densities of small-diameter $(<50 \mathrm{~nm})$ multi-walled nanotubes (MWCNTs) are required, as opposed to thick mats of tubes. In other words, the ability to grow a few discrete and separate small-diameter nanotubes within a specified area, in the 
plane of the growth substrate, is essential for realizing low threshold field nanotube-based electronic devices.

The technique used for CNT growth is often some form of catalyst assisted chemical vapor deposition (CVD), in which the growth process involves the use of fine particles of some transition metal catalyst (for instance $\mathrm{Ni}$ ) on a heated substrate (typically $700-900{ }^{\circ} \mathrm{C}$ ) that is exposed to a gaseous carbon source such as methane, ethylene or acetylene. CVD methods have replaced high-temperature methods like arc-discharge (in an atmosphere of hydrogen or argon) or laser ablation because they are more promising in terms of CNT deterministic growth (morphology, structure and density). They include thermal CVD [1], direct current plasma-enhanced CVD (dc PECVD) [2], microwave PECVD [3], hot-wire (HW) CVD [4] and HW dc PECVD [5,6].

The present paper had two objectives. First, it was necessary to demonstrate the possibility of controlling the synthesis of well-aligned MWCNTs in a reactor combining both HWCVD and dc PECVD techniques, using the $\mathrm{C}_{2} \mathrm{H}_{2} / \mathrm{NH}_{3} / \mathrm{H}_{2}$ gas mixture. This problem was solved recently [7]. The second objective was the control of the size and location of catalyst nanoparticles, and thus the control of the CNT diameters and their arrangement in regular arrays in order to maximize the electron emission from such CNT arrays. Up to now, most attempts have been made, based on the synthesis of regular arrays of oriented nanotubes on mesoporous silica [8] or on porous silicon [9], using thermal CVD. This is why growth using HW dc PECVD coupled with various catalyst patterning techniques should be attempted.

\section{Experimental details}

A schematic description of the experimental HW dc PECVD set-up has been made earlier [7]. The tungsten filament $(0.38 \mathrm{~mm}$ in diameter) is powered by a dc source around $13 \mathrm{~A}(250 \mathrm{~W})$, allowing the filament temperature, measured with an infrared pyrometer, to stabilize at $\mathrm{rV} 1800{ }^{\circ} \mathrm{C}$. In the gas mixture injected into the reactor, acetylene $\left(\mathrm{C}_{2} \mathrm{H}_{2}\right)$ is the deposition gas, ammonia $\left(\mathrm{NH}_{3}\right)$ and molecular hydrogen $\left(\mathrm{H}_{2}\right)$ are the etching gases. During the growth, the reactor pressure is maintained in the range $1^{-5} \mathrm{mbar}$, and the base pressure is as low as $10^{-7} \mathrm{mbar}$.

The synthesis process of MWCNTs in the HW dc PECVD reactor is based on formation of nickel nanoparticles by HWCVD, followed by CNT growth [7]. For the catalyst patterning, we focused on UV lithography to produce micron-size dots and on electron-beam lithography to provide submicron-size dots (from $500 \mathrm{~nm}$ down to loo $\mathrm{nm}$ ). For the latter case, positive resin was spin coated onto the substrate and care was taken to adjust the resin layer thickness and the electron-beam dose in order to control the dot size.

The thermal $\mathrm{SiO}_{2}$ or TiN diffusion barrier (10 $\mathrm{nm}$ thick) was deposited onto $300 \mathrm{~lm}$ thick highly n-doped (l 100 ) silicon substrate. Then the nickel catalyst ( $7 \mathrm{~nm}$ thick) was deposited. The diffusion barrier layer prevents the formation of $\mathrm{NiSi}_{\mathrm{x}}$ via $\mathrm{Ni}$ diffusion above $300{ }^{\circ} \mathrm{C}$ and maintains sufficient $\mathrm{Ni}$ particles for the catalytic nucleation and subsequent growth of the CNTs. CNT diameters depend upon the size of the metal catalyst particles [10,11].

The surface morphology of the grown MWCNTs was investigated with a FEG high resolution scanning electron microscope and the carbon bonding was assessed by Raman spectroscopy using $632.8 \mathrm{~nm}$ laser excitation [7]. Electron field emission was carried out using a triode setup in a vacuum chamber working at $10^{-6}$ Torr. The distance between the cathode and the grid is set to $1101 \mathrm{~m}$. The measured emitted current is the sum of the anode current and the grid current.

\section{Results and discussion}

First we demonstrate that it is possible to realize the CVD synthesis of aligned and bundled MWCNTs without utilizing mesoporous silica [8] or porous silicon [9], containing catalyst nanoparticles embedded in the pores. In a recent work, using a reactor combining both HWCVD and dc PECVD techniques, similar to that of Ren et al. [5], we have shown that mechanisms of CNT nucleation and growth can be approached by comparing these two CVD processes working separately or in a combined action, under identical deposition conditions [7]. We observed that with the dc PECVD process, yielding radicals and ions impinging on the cathode, growth of aligned CNTs was favored. The electric field in the cathode plasma sheath was equivalent to rvo.1 V/Im. When the HWCVD process was used exclusively with a filament temperature of $1800{ }^{\circ} \mathrm{C}$, for which a high concentration of atomic hydrogen was generated, dense tangled and curled up localized CNTs were grown. Moreover the substitution of ammonia for $\mathrm{H}_{2}$ had contradictory effects on the CNT structure for both processes, so that by using the HW dc PECVD process, optimum conditions for the gas mixture were necessary to obtain growth of dense $\left(\mathrm{rv}_{4} \cdot 10^{9} \mathrm{~cm}^{-2}\right)$ aligned CNTs, which corresponded to a minimization of the $\mathrm{NH}_{3}$ content [7]. Fig. 1 shows the SEM image of such a sample deposited under conditions described in Table $\mathbf{1}$ : $5 \% \mathrm{NH}_{3}$ and $85 \% \mathrm{H}_{2}$ with a total gas flow rate of $100 \mathrm{sccm}$ under a 1 mbar pressure, a potential drop of $420 \mathrm{~V}$ and a current density of ions impinging on the cathode of $1.5 \mathrm{~mA} / \mathrm{cm}^{2}$, and a filament temperature $T_{\mathrm{f}}$ of $1800{ }^{\circ} \mathrm{C}$. The CNT diameter ranges from 30 to $100 \mathrm{~nm}$ and the CNT length from 1.8 to $2.21 \mathrm{~m}$. Compared to the self-oriented arrays of CNTs synthesized on patterned porous silicon substrate where the nanotubes within each block interact via van der Waals forces and where the diameter distribution is narrow $(16 \pm 2 \mathrm{~nm})$ [9], we observe a broad diameter distribution $(65 \pm 35 \mathrm{~nm})$. Ni can be seen at the apex of CNTs in Fig. 1, which is the signature of a tip growth mode and which indicates weak interactions at the interfaces between the CNTs, in contrast to porous silicon where a base growth mode dominates [9]. 


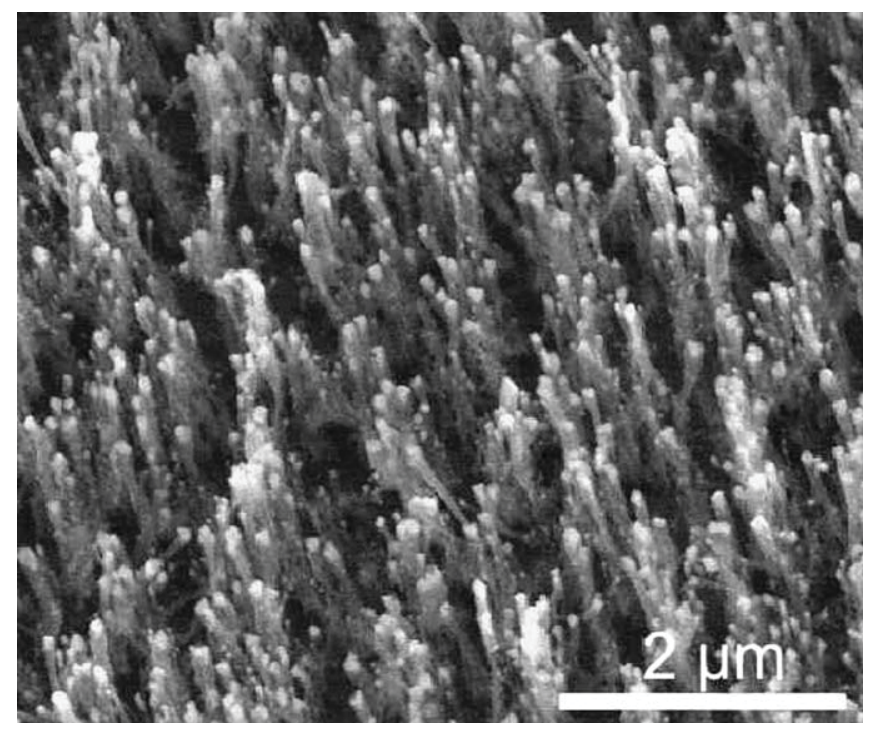

Fig. 1. SEM image (observation angle $45^{\circ}$ ) of sample $\mathbf{1}$ (see Table $\mathbf{1}$ for growth conditions).

In the second part of this work, we focus on the synthesis of arrays of a few discrete and separate CNTs within a specified area, which should be useful for many nanotubebased electronic devices. Some numerical studies on the assessment of the local electric field in the vicinity of the CNT tips for an array of aligned CNTs consider two factors: one internal factor describing the CNT structure (sensitive to the CNT diameter), one external factor describing the influence of the neighboring CNTs $[12,13]$. It was calculated, for a given CNT length, that the emission current density from such an array of CNTs increases rapidly when their diameter decreases from $80 \mathrm{~nm}$ to $20 \mathrm{~nm}$ and when the ratio (nanotube spacing)/(nanotube length) approaches 2.3 [13]. Experimental results concerning arrays of nanotube blocks (ultrahigh-density $\mathrm{rvio}^{\mathbf{1 1}} \mathrm{cm}^{-2}$ ) synthesized on patterned porous silicon [9] confirm this analysis: electric fields about $6 \mathrm{~V} / \mathbf{1 m}$ were necessary to reach current densities as low as $10 \mathrm{~mA} / \mathrm{cm}^{2}$, which means that the field screening effect plays a dominant role in these CNT blocks. Thus, we tried to get high electron field emission from arrays of MWCNTs grown by HW dc PECVD. For this purpose, square arrays of $\mathrm{Ni}$ catalyst dots, of different sizes, with various lattice translation vectors (pitches) were realized, using two patterning techniques: optical UV lithography (with a resolution of $\mathbf{1} \mathbf{I m}$ ) and electron-beam lithography (with a resolution of $40 \mathrm{~nm}$ ).

Fig. 2(A) is the SEM image of sample 2 deposited under conditions similar to those of sample 1 (see Table $\mathbf{1}$ ). UV lithography was used with a pitch of $4 \mathbf{I m}$. For each dot, there are rv25 almost aligned $C$ nanotubes whose diameter

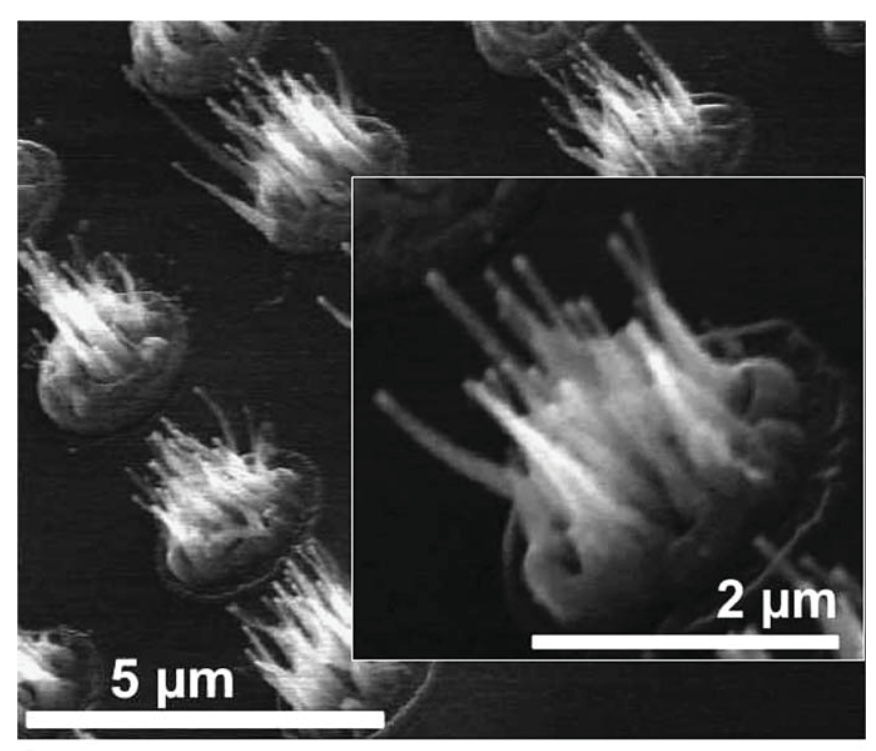

A

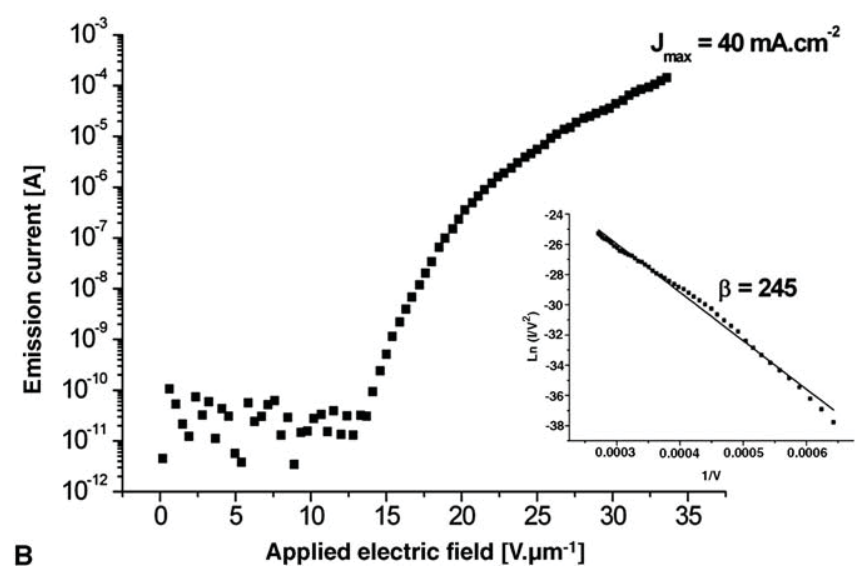

Fig. 2. (A) SEM image of sample 2 (see Table $\mathbf{1}$ for growth conditions). (B) Emission current density versus applied field characteristic of sample 2. The insert shows the fitting of J-E characteristics according to the FowlerNordheim equation.

Table 1

Growth conditions for combined HW dc-PECVD processes

\begin{tabular}{|c|c|c|c|c|c|c|}
\hline Sample & $\begin{array}{l}\text { Gas mixture, } \\
\mathrm{C}_{2} \mathrm{H}_{2}: \mathrm{NH}_{3}: \mathrm{H}_{2}(\%)\end{array}$ & $\begin{array}{l}\text { Pressure } \\
\text { (mbar) }\end{array}$ & $\mathrm{T}_{\mathrm{S}}\left({ }^{\circ} \mathrm{C}\right)$ & $\begin{array}{l}\text { dc-PE activation, } \\
\mathrm{V}_{\mathrm{A}-\mathrm{C}}(\mathrm{V}) \cdot \mathbf{J}_{\mathrm{C}}^{\mathrm{a}}\left(\mathrm{mA} / \mathrm{cm}^{2}\right)\end{array}$ & $\begin{array}{l}\text { HW activation, } \\
\mathrm{P}(\mathrm{W}) / \mathrm{T}_{\mathrm{f}}\left({ }^{\circ} \mathrm{C}\right)\end{array}$ & $\begin{array}{l}\text { Growth time } \\
(\min )\end{array}$ \\
\hline $\mathbf{1}$ & $10: 05: 85$ & 1 & 620 & $420 \cdot 1.5$ & $250 / 1800$ & 15 \\
\hline 2 & $10: 05: 85$ & 2.5 & 650 & $400 \cdot 4.4$ & $300 / 1850$ & 20 \\
\hline 3 & $10: 02: 88$ & 1.5 & 660 & $440 \cdot 3 \cdot 3$ & $250 / 1800$ & 15 \\
\hline 4 & 10:02:88 & 2 & 660 & $390 \cdot 4.4$ & $250 / 1800$ & 30 \\
\hline 5 & $15: 05: 80$ & 2.5 & 660 & $390 \cdot 8.9$ & $250 / 1800$ & 15 \\
\hline
\end{tabular}

The substrate consisted of $\mathrm{Ni}(7 \mathrm{~nm}) / \mathrm{TiN}(10 \mathrm{~nm}) / \mathrm{Si}(100)$ for all samples except sample 2 for which substrate was $\mathrm{Ni}(7 \mathrm{~nm}) / \mathrm{SiO}{ }_{2}(10 \mathrm{~nm}) / \mathrm{Si}(100)$.

${ }^{a} \mathrm{~V}_{\mathrm{A}-\mathrm{C}}$ : potential drop between the anode and the cathode; $\mathrm{J}_{\mathrm{C}}$ : current density of ions impinging on the cathode. 
and length is in the range $60-120 \mathrm{~nm}$ and $2-2.6 \mathrm{Im}$, respectively. No CNTs have been observed between dots. In Fig. 2(B) is plotted the emission current versus the applied field: the threshold electric field is $16 \mathrm{~V} / \mathbf{I m}$ and the maximum emission current density is $40 \mathrm{~mA} / \mathrm{cm}^{2}$ for a field of $33 \mathrm{~V} / \mathbf{I m}$. The field enhancement factor $\mathrm{b}$, as deduced from the Fowler-Nordheim fit, is around 240. The weak electron emission obtained is attributable partly to the large CNT diameters and their broad length distribution, and partly to the screening effect inside each $\mathrm{Ni}$ dot. A limitation of the emission current is also expected due to the resistivity of the silica barrier layer used for this sample. Fig. 3(A) is the SEM image of sample 3 deposited under conditions of Table 1. Compared to sample 2, the pressure was lower (1.5 mbar) and the $\mathrm{V}_{\mathrm{A}-\mathrm{C}}$ was higher $(440 \mathrm{~V})$, which favors smaller CNT diameters, narrowing of length distribution and better alignment. For this sample, for which UV lithography was used with a pitch of $4 \mathrm{Im}$, the maximum

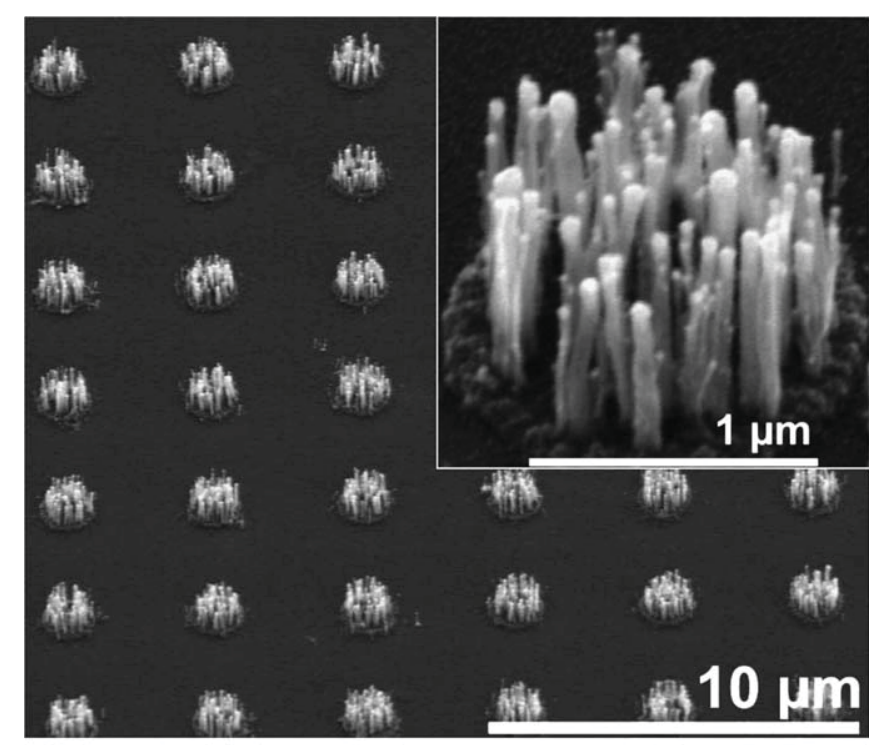

A

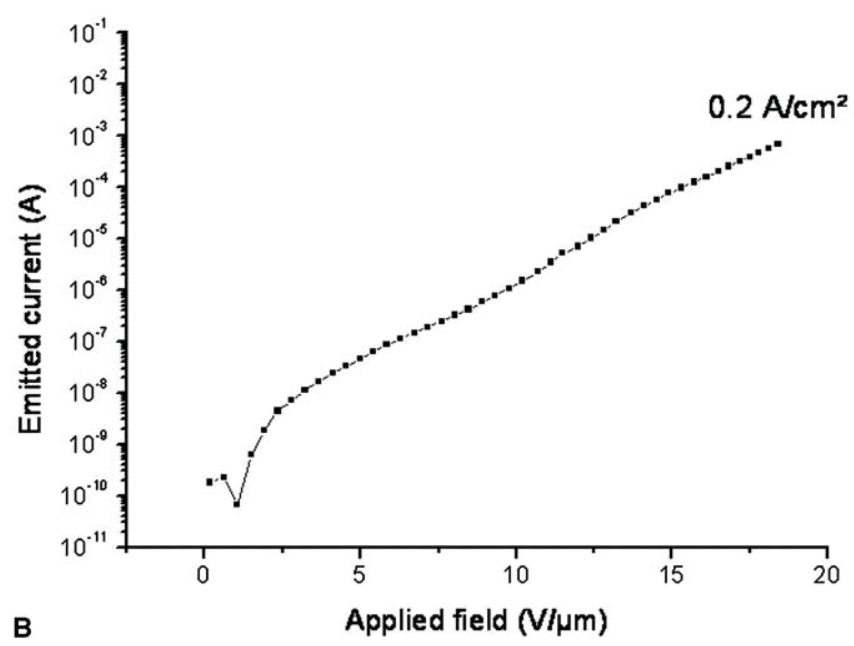

Fig. 3. (A) SEM image of sample 3 (see Table $\mathbf{1}$ for growth conditions). (B) Emission current density versus applied field characteristic of sample 3. emission current density is found to be $200 \mathrm{~mA} / \mathrm{cm}^{2}$ for a field of $18 \mathrm{~V} / \mathbf{1 m}$ (Fig. 3(B)). Thus, in sample 3, in comparison to sample 2, several CNT tips contribute to the emission of electrons, and thus reinforce the emission current, even though the screening effect between these CNTs is always dominant.

Fig. 4(A) is the SEM image of sample 4 deposited under conditions of Table 1. Electron-beam lithography with a resolution of $100 \mathrm{~nm}$ was used with a pitch of $10 \mathrm{Im}$. On each Ni dot, we observe the growth of a single MWCNT with a length of $1.5 \mathrm{Im}$ and a diameter of $50 \mathrm{~nm}$ at the apex. In Fig. 4(B) is plotted the emission current versus the applied field: the threshold electric field is $8 \mathrm{~V} / \mathbf{l m}$ and the maximum emission current density is $0.4 \mathrm{~A} / \mathrm{cm}^{2}$ for a field of $20 \mathrm{~V} / \mathrm{Im}$. The field enhancement factor $\mathrm{b}$, as deduced from the Fowler-Nordheim fit, is around 430. Compared to sample 2 (Fig. 2), the lower threshold field and the higher electron emission current are attributable
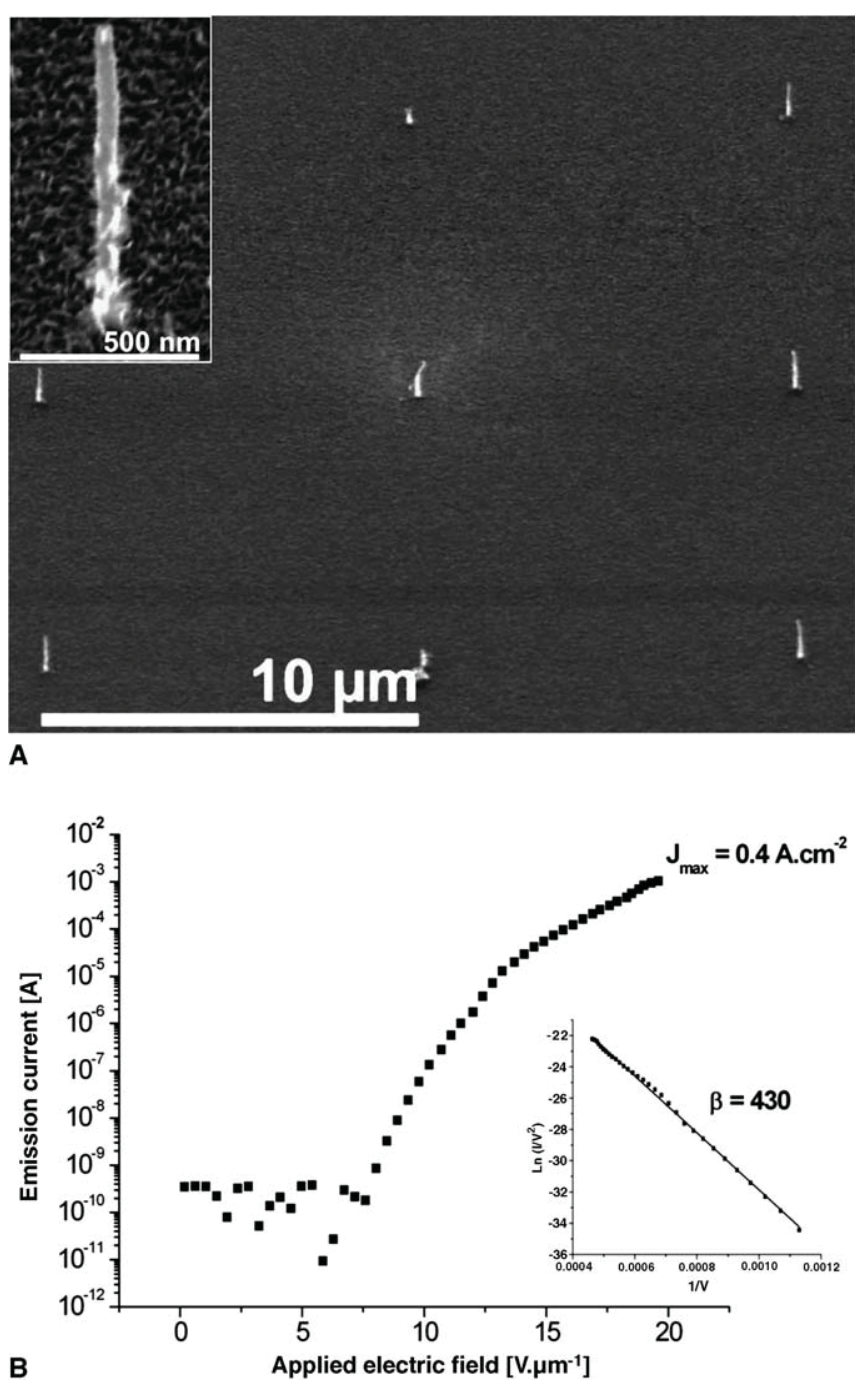

Fig. 4. (A) SEM image of sample 4 (see Table $\mathbf{1}$ for growth conditions). (B) Emission current density versus applied field characteristic of sample 4 . The insert shows the fitting of J-E characteristics according to the FowlerNordheim equation. 
to perfectly aligned CNTs without any screening effect (the spacing between nanotubes is about six times as big as the nanotube length). Similar field emission results have been obtained through the realization of individual MWCNTs under slightly different deposition conditions (different gas mixture, see sample 5 in Table $\mathbf{1}$ ), but using electronbeam lithography with the same resolution $(100 \mathrm{~nm})$ and with the same pitch (10 Im).

A more systematic work consisting of decreasing step by step the pitch between individual nanotubes, while keeping the same growth conditions is in process of completion, in order to get stable emission current densities in excess of $1 \mathrm{~A} / \mathrm{cm}^{2}$, which is of interest for specific field emission displays such as the new generation of microwave amplifiers working at UHF (>30 GHz).

\section{Conclusion}

This work has shown that it is possible to control the synthesis of well-aligned MWCNTs in a reactor combining both HWCVD and dc PECVD techniques, using the $\mathrm{C}_{2} \mathrm{H}_{2}$ / $\mathrm{NH}_{3} / \mathrm{H}_{2}$ gas mixture. Optimum conditions for the growth of MWCNTs have been found, corresponding to a minimization of the $\mathrm{NH}_{3}$ content at $\mathrm{rv}_{5} \%$, with $\mathrm{rv}_{5} \% \mathrm{H}_{2}$. Keeping these growth conditions, we have demonstrated, with the use of electron-beam lithography (100 $\mathrm{nm}$ resolution), that square arrays of individual MWCNTs ( $50 \mathrm{~nm}$ in diameter) allowed to get high field emission current density (rvo.4 A/ $\mathrm{cm}^{2}$ ). Further work is necessary in order to get higher emission density useful for flat panel displays or vacuum microelectronic sources.

\section{Acknowledgements}

This work was supported by the CANAST project driven by the French Research Network in Micro and Nano Technologies and by the CNRS-KOSEF international joint research project, under Contract No. Fo1-2004-0oo10240-o.

\section{References}

[1] M.P. Siegal, D.L. Overmyer, P.P. Provencio, Appl. Phys. Lett. 8o (2002) 2171.

[2] V.I. Merkulov, D.H. Lowndes, Y.Y. Wei, G. Eres, E. Voelkl, Appl. Phys. Lett. 76 (2000) 3555.

[3] C. Bower, O. Zhou, W. Zhu, D.J. Werder, S. Jin, Appl. Phys. Lett. 77 (2000) 2767.

[4] K.H. Park, S. Choi, K.M. Lee, S. Lee, K.H. Koh, J. Vac. Sci. Technol. B19 (2001) 958 .

[5] Z.F. Ren, Z.P. Huang, J.W. Xu, J.H. Wang, P. Bush, M.P. Siegal, P.N. Provencio, Science 282 (1998) 1105.

[6] J.H. Han, W.S. Yang, J.B. Yoo, C.Y. Park, J. Appl. Phys. 88 (200o) 7363.

[7] C.S. Cojocaru, D. Kim, D. Pribat, J.E. Bourée, Thin Solid Films 501 (2006) 227.

[8] W.Z. Li, S.S. Xie, L.X. Qian, B.H. Chang, B.S. Zou, W.Y. Zhou, R.A. Zhao, G. Wang, Science 274 (1996) 1701.

[9] S. Fan, M.G. Chapline, N.R. Franklin, T.W. Tombler, A.M. Cassell, H. Dai, Science 283 (1999) 512.

[10] M. Chhowalla, K.B.K. Teo, C. Ducati, N.L. Rupesinghe, G.A.J. Amaratunga, A.C. Ferrarri, D. Roy, J. Robertson, W.I. Milne, J. Appl. Phys. 90 (2001) 5308.

[11] E.F. Kukovitsky, S.G. L'vov, N.A. Sainov, V.A. Shustov, L.A. Chernozatonskii, Chem. Phys. Lett. 355 (2002) 497.

[12] O. Gröning, O.M. Küttel, C.Y. Nasuno, M. Kondo, A. Matsuda, Appl. Phys. Lett. 78 (2001) 2330.

[13] D. Kim, J.E. Bourée, S.Y. Kim, Appl. Phys. A 83 (2006) 111. 